\title{
Impact of distance learning on the physical training of technical university students in the context of the COVID-19 virus pandemic
}

\author{
Nikita Zavodny ${ }^{l}$, Sergey Latyshev ${ }^{l}$, Elena Filippova ${ }^{2 *}$, and Stanislav Shengelaya ${ }^{3}$ \\ ${ }^{1}$ Don State Technical University, 344000, Rostov-on-Don, Russia \\ ${ }^{2}$ Rostov State Transport University, 344038, Rostov-on-Don, Russia \\ ${ }^{3}$ K.G. Razumovsky Moscow State University of Technologies and Management, 109004, Moscow, \\ Russia
}

\begin{abstract}
The conditions of the pandemic caused by the covid-19 virus have made significant changes in the lifestyle of student youth, as well as in the educational process in universities, including in physical education. The main emphasis was placed on the self-organization of physical culture and health-improving activities of students: lecture courses and theoretical and methodological classes were organized. The purpose of the study is to analyze the impact of distance learning on the lifestyle, physical training and functional state of students of the Don State Technical University; as well as identifying ways to improve the quality of distance learning. The study was carried out on the basis of the Don State Technical University in Rostov-on-Don with the participation of second and third year full-time students. Students took a questionnaire reflecting their self-assessment on the organization of independent physical training and well-being in selfisolation during the first wave of the COVID-19 pandemic. To study the physical training of the respondents, a comparative analysis of the results of the initial and control testing of basic physical qualities was used.
\end{abstract}

\section{Introduction}

\subsection{Relevance}

The relevance of conducting research on the impact of distance learning on the physical training of students is dictated by the most difficult situation in the world now - the pandemic caused by the COVID-19 virus. Today, the topic of the pandemic is the main one in the key means of mass communication. This virus is still very dangerous [1]. At the moment, more than three million people have been infected with it in the world. Experts have developed a set of sanitary and epidemiological measures and measures to counter this virus: people should stay at home, monitor personal hygiene (wash their hands and face more often), in public places, for example, in grocery stores and in public transport, wear protective masks and gloves ...

\footnotetext{
*Corresponding author: filippova-71@mail.ru
} 
In this situation, all Russian universities have moved to distance learning. This decision was made by the rectors of universities in order to prevent the spread of a new Coronavirus infection among students, teachers and, accordingly, their relatives and friends.

European universities were also forced to move to emergency distance learning $[2,3]$.

In connection with the need to observe the regime of self-isolation, university students have a rather acute problem. Staying at home and studying through electronic means of communication, they found themselves in unusual living conditions. First of all, their physical activity sharply decreased. In connection with this, many students felt significant restrictions in movement and experienced psychological discomfort from this [4].

Some authors note that the majority of students in distance learning conditions have changed diet and choice of consumed food [5,6].

Health is the basic need of every person, its main value. Physical education for university students is vital for maintaining health. They are contribute not only to the development of physical qualities, but also to relieve psycho-emotional stress [7, 8]. This is very important, since a long stay in self-isolation is stressful for any person.

In these conditions, the issues of modernization of the Russian education system as the basis for the social development of society, the security of the country and the well-being of citizens are reflected in the most important state documents: "On the basics of protecting the health of citizens in the Russian Federation"; "On education in the Russian Federation"; "On physical culture and sports in the Russian Federation." When the state consists of physically weakened and socially unhealthy youth, there can be no talk about the prosperity and well-being of the nation. The Declaration of Youth of the Fourth Conference of European Ministers of the World Health Organization (WHO) on Environment and Health (Budapest, June 2004) notes that "the health of young people has an indisputable value", which is beyond doubt.

President of the Russian Federation V.V. Putin determines the main direction of development of physical culture and sports in Russia until 2024 - the need to "increase the share of students who are systematically involved in physical culture and sports in the total population of this category of the population." In his opinion, "the achievement of the volume of weekly physical activity of the population should be from 6 to 12 hours, with at least three and four lessons, depending on the age and other characteristics of citizens." The result (until 2024) should be attracting more than half of the country's population $(55 \%)$ to physical culture and sports, while the number of student youth should be up to $80 \%[9,10]$.

In this regard, independent exercise is very important. Among the forms of self-study, scientists recommend morning exercises, which should include exercises for all muscle groups, thereby helping to awaken the body. In addition to morning exercises, experts recommend that students do physical exercises during the day, for example, between classes. This will relieve stress, fatigue and increase concentration [11]. Self-training is another form of self-isolation training $[12,13,14]$. Their experts recommend doing it 3-4 times a week, lasting 40-90 minutes. In this case, one should take into account the level of one's preparedness and state of health at the time of exercise.

The World Health Organization for Europe recommends exercising at least 150 minutes of moderate intensity per week during a pandemic. An alternative is vigorous physical activity for at least 75 minutes per week. Simple and safe recommendations for performing exercises of various intensities are reflected in a special guide developed by WHO / Europe. The main emphasis in them is placed on exercises of light and medium intensity in an aerobic mode: jogging, cycling, Nordic walking in the fresh air. Classes have been developed in a personal home (apartment, house): exercises with fitballs, aerobics and yoga, exercises with a barbell, dumbbells, etc. All these exercises train the respiratory system, increase the respiratory volume of the lungs, which is very important in the context of the pandemic caused by the COVID-19 virus [14]. 
The purpose of the work is to analyze the impact of distance learning on the physical training of students of the Don State Technical University, as well as to identify ways to improve the quality of distance learning in Russian universities.

\section{Research methods and procedure}

The study was conducted in 2019-2021 on the basis of the Don State Technical University in Rostov-on-Don within the framework of the discipline "Physical culture and sports". It was attended by students of the second and third courses of full-time education of the main and preparatory medical groups of DSTU.

Due to the fact that due to the lack of the opportunity to study in the online system together with their teachers (lack of the necessary technical equipment, both for the students themselves and for teachers), physical education classes by university teachers were mainly carried out in a recommendatory form. For students who are self-isolating and studying remotely, physical education teachers recommended daily morning hygienic exercises and at least twice a week for 40-60 minutes to perform targeted physical exercises that develop various muscle groups.

When independently searching for physical exercises on the Internet, students were recommended to use only proven online resources, if necessary, consult with their teachers. After lengthy lessons in the distance learning system (in other academic subjects), it was proposed to perform simple physical exercises, such as walking in place, swinging arms and legs, bending the body, squatting, etc. At the end of online non-physical activities or during a long break, it was suggested to do exercises like shaping, aerobics, or just dance. These classes, in addition to the development of various systems of the body, have a positive effect on the psycho-emotional state of a person. At the same time, it was not possible for the teachers to check whether the students were fulfilling the recommendations issued.

Six months later, the students passed a questionnaire reflecting their self-assessment on the organization of independent physical training and well-being in conditions of selfisolation.

The aspects of self-study, attitude to a healthy lifestyle, well-being, daily physical activity, organization of the day, bad habits were considered.

To study the physical training of students, a comparative analysis of the results of the initial (2019/20 academic year) and control (2020/21 academic year) testing of basic physical qualities was used: speed - running at $100 \mathrm{~m}$, endurance - running $3000 \mathrm{~m}$ and strength - pulling up on crossbar (boys), pull-ups on a low crossbar (girls).

To track changes in the functional state of students, the results of some functional tests were studied. The Stange and Genchi tests were used to study the training of the students 'body and its sensitivity to oxygen. The performance of the students' bodies was assessed using the Rufier test. The Pignelo index was used to study the physique of students.

\section{Results and discussion}

\subsection{Lifestyle research}

The results of the questionnaire showed that in the conditions of self-isolation, all the interviewed students were independently engaged in physical culture, including morning hygienic gymnastics. At the same time, morning exercises were performed daily by only $7 \%$ of students (Fig. 1.) 


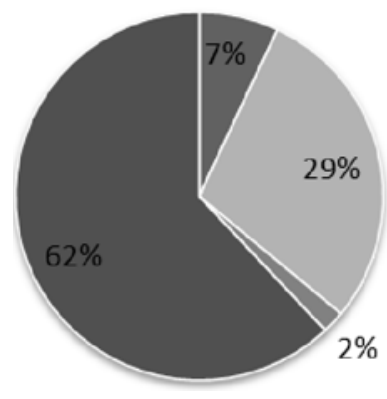

- daily $7 \%$

= 3-4 times a week $29 \%$

= sometimes $2 \%$

- were not perfomed $62 \%$

Fig. 1. Performing morning exercises

In addition to morning exercises, only $38 \%$ of the respondents engaged in purposeful physical exercises. Of these, three to four times a week, only $11 \%$. 10\% had physical activity only from time to time, but not less than once every two weeks (Fig. 2). Also, it was found that $7 \%$ of students studied with friends or relatives, "for the company" two or three times a week.

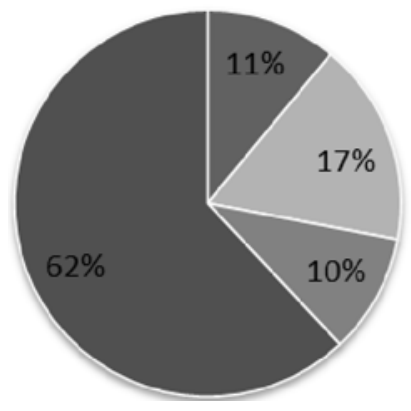

- 3-4 times a week $11 \%$

=1-2 times a week $17 \%$

= sometimes, when I remember $10 \%$

- I don't do it at all $62 \%$

Fig. 2. Physical activity per week

As it turned out, more than $80 \%$ of respondents do not have any sports equipment at home, and training with their own weight seems boring and ineffective to them (Fig. 3).

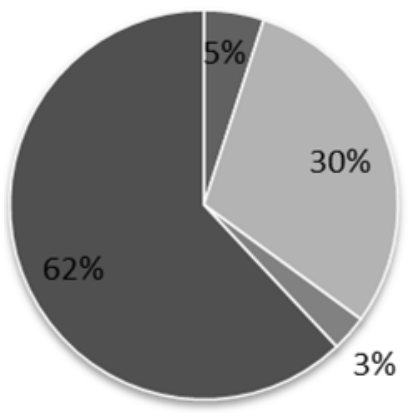

- 3-4 times a week $5 \%$

=1-2 times a week $30 \%$

- several times a week $3 \%$

were not performed

$62 \%$

Fig. 3. Performing bodyweight exercises

Only $12 \%$ of respondents performed exercises with equipment on a regular basis (three to four times or more per week) (Fig. 4). 


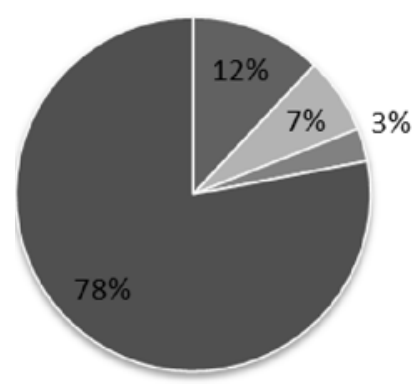

\author{
- 3-4 times a week \\ $12 \%$ \\ 1-2 times a week \\ $7 \%$ \\ - several times a \\ week 3\% \\ were not \\ performed $78 \%$
}

Fig. 4. Performing exercises with sports equipment

At the same time, $79 \%$ of respondents assessed their physical activity in distance learning as low. Also, most of the respondents showed that they do not know how to build a training program independently: they do not know exercises, dosage, impact of load on the body.

In addition, about $68 \%$ could not find motivation for independent sports activities, and $12 \%$ of the respondents believe that they need a global change in their motor regime.

In addition, many students complained about the lack of favorable conditions for doing exercises: modest living conditions and, in this regard, the lack of space for physical exercise; the presence in the apartment of other family members who are currently also busy with studies or work in self-isolation.

Some of the respondents associate the decrease in physical activity with the financial costs of purchasing equipment, sports equipment and sports uniforms and the lack of financial opportunities for this (low or no stipend, the need to pay for tuition and housing, etc.). Mandatory free classes at the university are a more acceptable option for them. Since the motivation is often the test, the time for classes is already built into the curriculum, there is a large sports base and the choice of physical activity, as well as the absence of financial costs.

The study found that $60 \%$ of students experienced an increase in body weight between March 2020 and March 2021 (Fig. 5). So, 9\% of the respondents gained weight from 7 to $12 \mathrm{~kg}$. For $19 \%$ of the respondents, changes in weight increased by $3-5 \mathrm{~kg}$. The rest of the weight gain was $1-2 \mathrm{~kg}$. They associate this fact with a decrease in physical activity and malnutrition. At the same time, $32 \%$ of the tested responded that they try to monitor the caloric content of their diet and rarely violate the diet. Almost all respondents see the need for a global change in their diet and exercise regimen.

Since the testing was anonymous, $68 \%$ of the students admitted that they abused alcohol (more often beer and wine) and fast food. During the survey, important attention was paid to the state of health of the respondents during the period of isolation.
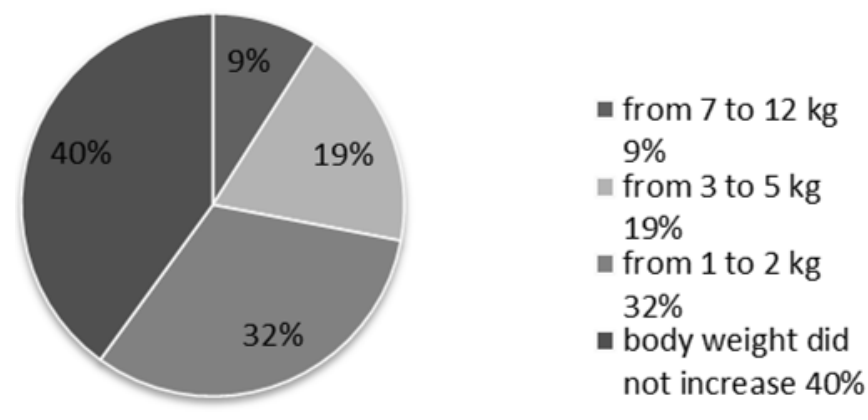

Fig. 5. Increase in body weight 
Sleep disorders were observed in $43 \%$ of the respondents. At the same time, $18 \%$ quite often noted a deterioration in their well-being - lethargy, decreased mental performance (Table 1).

Table 1. Indicators affecting health

\begin{tabular}{|c|c|c|c|}
\hline \multirow{2}{*}{ Indicators } & \multicolumn{3}{|c|}{ Self-assessment } \\
\cline { 2 - 4 } & $\begin{array}{c}\text { Often (more } \\
\text { than 3 times a } \\
\text { week) }\end{array}$ & $\begin{array}{c}\text { Occasionally (1-2 } \\
\text { times a week) }\end{array}$ & $\begin{array}{c}\text { Sometimes (1-2 } \\
\text { times a month) } \\
393229\end{array}$ \\
\hline Eating disorders & 39 & 32 & 29 \\
\hline Sleeping disorders & 43 & 31 & 36 \\
\hline Deterioration of health & 18 & 39 & 43 \\
\hline
\end{tabular}

\section{Physical training study}

In the study of physical training of students, a comparative analysis of the results of the initial (2019/20 academic year) and final (2020/21 academic year) testing of basic physical qualities was carried out. Control measurements showed a deterioration in the performance of the majority of subjects in the endurance test $-70 \%$ of boys and $87 \%$ of girls (Fig. 6).

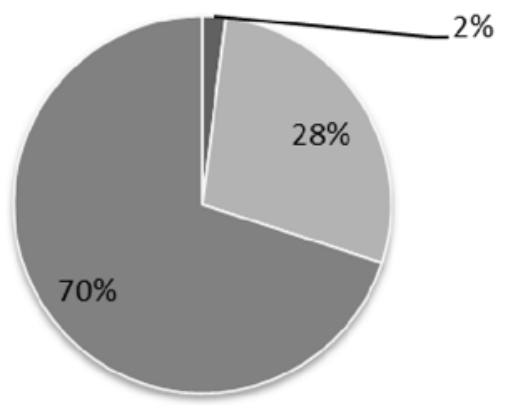

$$
\begin{aligned}
& \text { the result improved } \\
& 2 \% \\
& \text { the result remained } \\
& \text { the same } 28 \% \\
& \text { the result decreased } \\
& 70 \%
\end{aligned}
$$

Fig. 6. Running at $3000 \mathrm{~m}$

The test results in running at 100 meters showed the smallest decrease in indicators (Fig. 7). Only a third of boys and girls could not repeat last year's result.
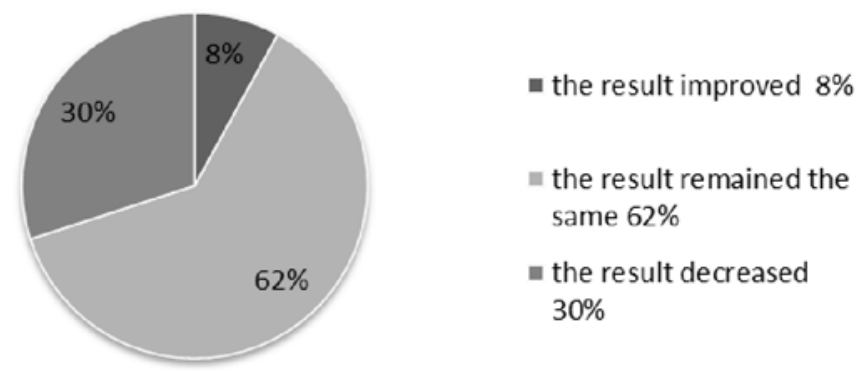

Fig. 7. Running 100 meters

The dynamics of strength indicators was heterogeneous. For girls, the decrease in results in pull-ups on a low bar, $90 \mathrm{~cm}$ high was $42 \%$, and for boys in pull-ups on a high bar $-30 \%$ (Fig. 8a, b). 


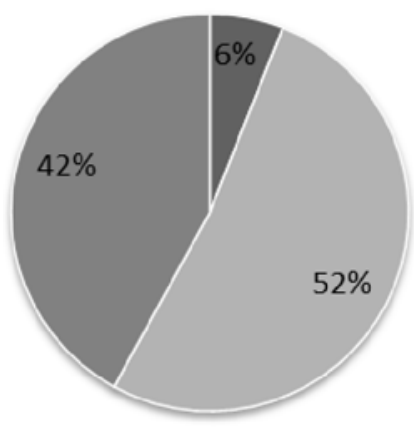

$$
\begin{aligned}
& \text { - the result } \\
& \text { improved } 6 \% \\
& \text { the result } \\
& \text { remained the } \\
& \text { same } 52 \% \\
& \text { the result } \\
& \text { decreased } \\
& 42 \%
\end{aligned}
$$

Fig. 8. (a) Pull-ups (girls)

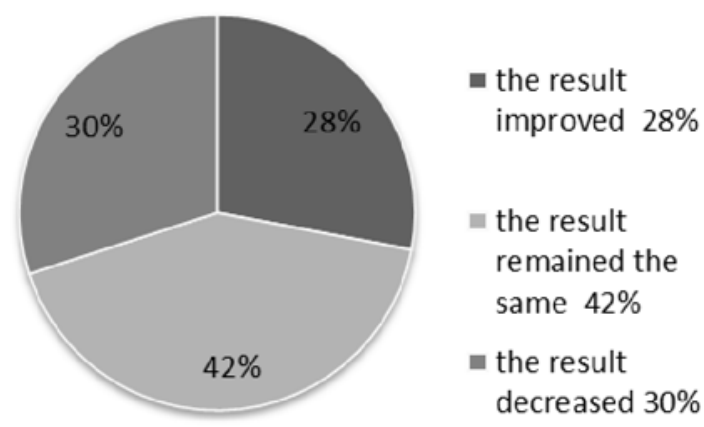

Fig. 8. (b) Pull-ups (boys)

\section{Functional state research}

The obtained indicators of the Stange test in $70 \%$ of the subjects were in the range of average values.

At the same time, the indicators of the Genchi test were below average in $58 \%$ of the respondents.

The data obtained using the Rufier test revealed low performance in a significant part of the subjects. There were no students with heart failure (Fig. 9).

The results of the Pignet index revealed a disproportionate physique in more than half $(51 \%)$ of the students.

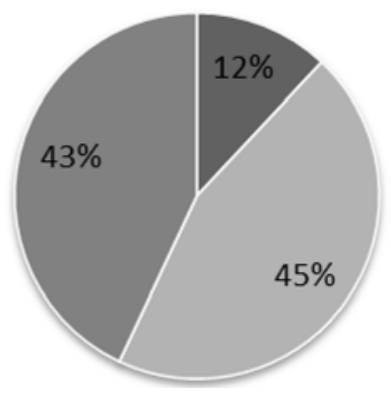

aood $12 \%$

average $45 \%$

- satisfactory $43 \%$

Fig. 9. Performance 


\section{Conclusion}

Based on the above, it can be argued that distance learning of students of a technical university changed their usual daily routine, level of physical activity and health, as a result of which the physical training of students and their functional capabilities significantly deteriorated in the 2020/21 academic year compared to the previous academic year.

Distance learning in the field of physical culture and sports does not meet the needs of student youth. Therefore, one of the main tasks of the distance course of the subject "Physical culture and sports" in the university should be the formation of personal physical culture, a healthy lifestyle and health improvement of students. At the same time, the main task of teachers is to explain to students the dominant role of physical culture in strengthening their health, to convince students of the importance of independent physical exercises.

To improve the quality of training students in the academic subject "Physical culture and sport" in technical universities, innovative approaches are needed to update the content of educational programs, including distance learning programs, by creating new training courses that combine modern scientific achievements from various branches of science.

\section{Reference}

1. Matt Pelton, Daniela Medina, Natasha Sood, Kaleb Bogale, Lindsay Buzzelli, Joshua Blakerand etc, ANNALS OF EPIDEMIOLOGY 56, 26+ (2020). DOI: 10.1016 / j.annepidem.2020.10.004.

2. Santiago Iglesias-Pradas, Angel Hernandez-Garcia, Julian Chaparro-Pelaez, Jose Luis Prieto, Computers in human behavior 119, 106713 (2021). DOI: 10.1016 / j.chb.2021.106713.

3. Martin Daumiller, Raven Rinas, Julia Hein, Stefan Janke, Oliver Dickhaeuser, Markus Dresel, Computers in human behavior 118, 106677 (2021). DOI: 10.1016 / j.chb.2020.106677.

4. Tatyana Simina, Elena Lyubina, Svetlana Taranova, Irina Puchkova, Peculiarities of organizing physical culture classes in conditions of self-isolation, Actual problems, modern trends in the development of physical culture and sports, taking into account the implementation of national projects, materials of the All-Russian scientific and practical conference with international participation ... publishing house: Russian Economic University named after G.V. Plekhanov, (2020), pp. 317-321.

5. Patricia Powell, Sheleigh Lawler, Jo Durham, Katherine Cullerton, APPETITE 161, 105130 (2021). DOI: 10.1016 / j.appet.2021.105130.

6. Aytan Novil Kyzy Jabbarova, Anastasia Eremia, Dynamics of changes in nutritional hygiene and BMI indicators in medical students during a pandemic and self-isolation, Collection of articles based on materials of the XXXIV student international scientific and practical conference "International Center for Science and Education" (Moscow) "Natural and Medical Sciences, student scientific forum", (2020), pp. 2-23.

7. Anatoly Opletin, Theory and practice of physical culture 6, 96 (2016).

8. Elena Filippova, Zhanna Pasechnik, On the question of the benefits of physical culture and sports, Materials of the IX International Scientific and Practical Conference "Physical Culture, Sport, Tourism: Innovative Projects and Best Practices" 2 (38), 126130 (2020).

9. Meeting of the Council for the Development of Physical Culture and Sports. March 24, 2014. [Electronic resource]. URL: http://kremlin.ru/events/president/news/20635. 
10. Igor Ponomarev, Viktor Litvinov, Oleg Ponomarev, Humanitarian, socio-economic and social sciences 4, (2016).

11. Alexey Karasev, Olga Kazakova, Lidia Ivanova, Alla Danilova, Scientific notes of the University named after P.F. Lesgaft 5 (183), 195-199 (2020).

12. Yulia Polshchikova, Elena Vinyukova, Gulmira Shchukina, Alexander Krashilin, Lesgaft 3 (181), 351-354 (2020).

13. Daria Strepetkova, Valentina Brykina, SCIENCE-2020 2 (38), 34-40 (2020).

14. Naur Nutsalov, Scientific notes of the University named after P.F. Lesgaft 10 (188), 263-266 (2020).

15. Global recommendations on physical activity for health. Available at: https://www.who.int/dietphysicalactivity/factsheet_recommendations/ru/ (Date accessed: 04/22/2020). 